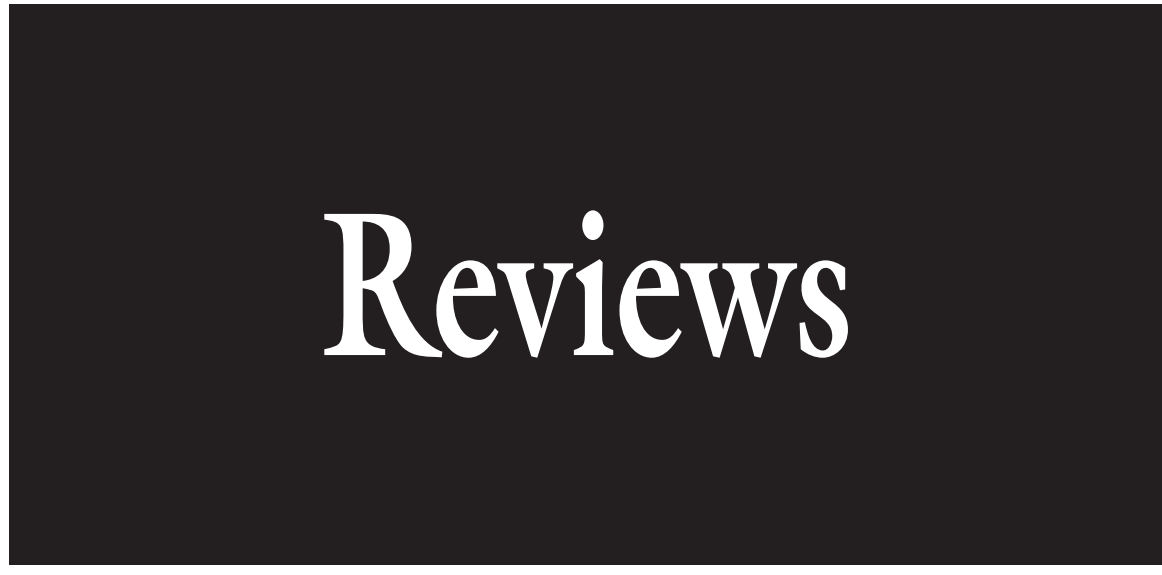

\section{Root Piece Planting in Sweetpotato- A Synthesis of Previous Research and Directions for the Future}

\author{
Nicholas A. George, Kenneth V. Pecota, Blake D. Bowen, \\ Jonathan R. Schultheis, and G. Craig Yencho ${ }^{1}$
}

ADDITIONAL INDEX WORDS. alternative uses, processed foods, industrial products.

Summary. Sweetpotato (Ipomoea batatas) is traditionally grown for fresh consumption, particularly in developed nations, but it is increasingly being used for alternative markets such as processed foods and industrial products. Sweetpotato is well suited for these end uses but its utilization is limited due to high production costs. These costs are primarily the result of high labor inputs. As a vegetatively propagated crop, sweetpotato is typically planted using unrooted plant cuttings, or "slips," which requires hand labor at several stages. Consequently, planting costs can be as high as $\mathbf{2 0 \%}$ of total production costs. As an alternative to slips, sweetpotato can be established using root pieces, similar to the seed piece system used for potato (Solanum tuberosum). This system can be readily mechanized and therefore has the potential to reduce labor demands. Root piece planting has been investigated several times since the 1940 s but is not reported to be in large-scale commercial use anywhere in the world. In this work, we review the research literature relating to root piece planting in sweetpotato. This literature demonstrates that it is possible for sweetpotato root pieces to produce yields comparable to slips, but that in most cases yields from root pieces are usually lower than from slips. We conclude that given suitable cultural management and appropriate varieties, it may be possible to successfully produce sweetpotato using root pieces. More work is necessary to develop root piece planting as a viable alternative to slips in sweetpotato production. This work should include the selection and breeding of adapted varieties, evaluation of the economics of sweetpotato production using root pieces, development of planting equipment suited to sweetpotato root pieces, and examination of chemical treatments to improve success of root piece planting.

S weetpotato is one of the world's most important and widely grown starchy crops, with annual production in over 110 countries currently

We sincerely thank Dr. Chris Gunter, Dr. Sally Thompson, Mr. Mark Clough, and Mr. Steven Todd for providing reviews of the draft manuscript of this work. This work was conducted as part of a project funded by the Biofuels Center of North Carolina.

Department of Horticultural Science, North Carolina State University, 214 Kilgore Hall, Campus Box 7609 , Raleigh, NC 27695

${ }^{1}$ Corresponding author. E-mail: Craig_Yencho@ncsu.edu. estimated to total 114 million tonnes (Food and Agriculture Organization of the United Nations, 2010). In developed nations, sweetpotato is primarily grown for fresh consumption or as a canned product, but the markets for sweetpotato as a value-added processed food and bio-based industrial products are growing. For example, sales of processed sweetpotato in the United States increased by an average of $20,000 \mathrm{lb}$ per year during 2007 09 , to a total close to $110,000 \mathrm{lb}$ in 2009 (U.S. Sweet Potato Council, 2011). Sweetpotato can also produce large yields of biomass suitable for conversion to industrial products (Ziska et al., 2009). For example, the starch can be converted to simple sugars and then used to produce plastics or fuels, such as ethanol and butanol (Klass, 1998).

In all parts of the world sweetpotato crops are propagated using unrooted sprouts or vine cuttings (Loebenstein and Thottappilly, 2009). Sweetpotato is a perennial species but can only be grown year-round in tropical and subtropical climates. In these climates, vine cuttings are taken from existing crops. Sweetpotato can be grown successfully in temperate regions, but only as a summer annual. In temperate regions, sweetpotato roots are stored over winter, bedded in early spring, and the sprouts from these roots, known as "slips," are then used for propagation.

Propagation of sweetpotato crops from slips in temperate regions is demanding in terms of time, expense, and labor. The "seed" roots must be over wintered, which incur storage costs. Large field crews are then required for manual bedding of roots, cutting of slips, and transplanting. In the United States, estimates of the total production costs of sweetpotato range from $\$ 1800 /$ acre to $\$ 3400 /$ acre, with slip production and planting being $15 \%$ to $20 \%$ of this (Estes et al., 2002; Hinson and Boudreaux, 2007; Martin et al., 2000; Mississippi State University, 2007).

As alternative end uses of sweetpotato are developed, the need to make production less costly and labor intensive becomes more important. An alternative to propagating sweetpotato with slips is to use small roots or, more commonly, pieces of roots.

\begin{tabular}{llll}
\hline $\begin{array}{l}\text { Units } \\
\text { To convert U.S. to SI, } \\
\text { multiply by }\end{array}$ & U.S. unit & SI unit & $\begin{array}{l}\text { To convert SI to U.S., } \\
\text { multiply by }\end{array}$ \\
\hline 0.4047 & acre(s) & ha & 2.4711 \\
0.4536 & $\mathrm{lb}$ & $\mathrm{kg}$ & 2.2046 \\
28.3495 & $\mathrm{oz}$ & $\mathrm{g}$ & 0.0353 \\
0.9072 & ton $(\mathrm{s})$ & $\mathrm{t}$ & 1.1023
\end{tabular}

\footnotetext{
Hortednulogy $\cdot$ December $201121(6)$
} 
This is similar to the propagation system used for potato and is also called "seed piece planting" or "direct planting." As is the case for potato, this method of propagation lends itself to mechanization, and therefore reduces labor requirements.

Root piece planting in sweetpotato has been investigated since the 1940 s but is not reported to be used commercially anywhere in the world. In this work, we review and synthesize the research literature relating to root piece planting in sweetpotato, assess the potential of root piece planting as a viable alternative to slips, and make recommendations for future research.

\section{Overview of root piece research}

There is a 70 -year history of published research relating to propagating sweetpotato using root pieces (Table 1). The research was primarily conducted in Japan and the United States, with the only sustained research effort undertaken by workers in Japan between the 1950s and 1970s, and the chronology in Table 1 shows that the majority of the research ceased after the 1980s. Much of the research is also reported in the "gray literature," obscure journals, brief conference abstracts or remains unpublished, making it challenging to thoroughly review the work. English translations of earlier Japanese research are also not always available, making it difficult for international researchers to access. Additionally, except for summaries of Japanese work before the 1970s (Ikemoto, 1971; Kobayashi, 1968), there has been no prior attempt to provide a comprehensive overview and synthesis of sweetpotato root piece research.

Perhaps as a consequence of this publication history, the body of research on sweetpotato root piece planting is frequently repetitive. For example, independent studies on the effects of seed piece size on the success of root piece planting were conducted in 1943, 1946, 1954, 1962, 1969, and 1982, all reaching effectively similar conclusions (Georgia Coastal Plain Experimental Station, 1943; Kays and Stutte, 1982; Kodoma, 1962; Kodoma et al., 1954b; Lutz et al., 1946; Nakazawa and Sano, 1969), and yet the present authors are aware of contemporary researchers examining root piece size effects. Such duplication could be avoided if previous research were more accessible. One of the prime motivations for this review is therefore to synthesize the state of knowledge regarding root piece planting in sweetpotato so as to make the findings more readily available and to foster future research.

Despite the repetition in the literature, several important themes relating to sweetpotato establishment from root pieces can be identified. These include the common problems experienced when planting root pieces and the influences of cultural management and genetic factors in overcoming these problems. These will be explored throughout the remainder of the review.

We also to wish to note that the present authors began research relating to sweetpotato root piece planting in the early 2000s. This work has included both cultural management studies and germplasm screening. The cultural management work involved studies of the effect of root piece, planting date, root piece size, and the effect of ethylene on root piece sizing and rotting. Breeding work has included germplasm screening and an investigation of the heritability of traits associated with root piece planting. This work is either in preparation for publication or on going.

\section{Root type nomenclature}

When grown from root pieces, sweetpotato can produce a number of different storage root types. Figure 1 depicts and summarizes the most common nomenclature used for storage roots arising from a root piece. "Mother pieces" result from the enlargement of the smaller planted root piece. Any new storage roots produced, aside from the mother piece, are termed "daughter roots." Daughter roots are typically divided into two classes: "direct daughter roots," produced directly from the planted mother piece, and "indirect daughter roots," produced from adventitious sprouts derived from the mother root. We recognize two further categories of storage roots, "enlarged sprouts" and "semi-indirect daughter roots." Enlarged sprouts arise from the thickening of adventitious sprouts that emerge from the planted root pieces. Semi-indirect daughter roots form from adventitious roots that emerge from the enlarged sprouts. Sweetpotato clones vary in the number and types of these root types that they produce. To aid in germplasm selection, Bouwkamp (1982) proposed a classification system to describe these different types and used this system to inform their selection activities (Fig. 2). The system categorized clones as producing direct daughter roots, indirect daughter roots, or no daughter roots, and within each of these categories as having mother pieces that enlarge, do not enlarge, or rot. These categories are nondiscrete, with intermediate types present, especially in terms of the extent of mother piece sizing (Bouwkamp, 1982).

\section{Common problems encountered from root piece planting}

Root piece planting can occasionally produce root yields and root quality comparable to slips, but most workers report that for the same clone yields and root quality from root pieces are generally inferior than from slips. Five, interrelated, factors are primarily responsible for sweetpotato root piece planting being less successful than planting with slips:

1) LOWER YIELDS FROM ROOT PIECES THAN SLIPS. Most studies report that total yields tend to be greater when a sweetpotato clone is established from slips rather than from root pieces. For example, Lutz et al. (1946) found that yields from root pieces for two clones were on average $59 \%$ that of slips. A recent 3-year study comparing several clones at two sites in North Carolina found the yield from root pieces was on average $49 \%$ lower than the yield from slips (Bowen, 2010). However, some workers have identified clones where slips and root pieces produce comparable yields. For example, Bouwkamp (1982) selected three clones which produced yields from root pieces that were within $5 \%$ of the same clones planted as slips.

2) Root PIECE ENLARgEMENT. Planted root pieces of sweetpotato regularly become a sink for photoassimilates and enlarge. In some cases, the enlarged mother pieces comprise most, or all, of the harvested storage root yield. The enlargement of the planted piece is undesirable because the mother piece tends to be deformed and cracked. This results in an increased propensity for rotting and severely limits the usefulness of mother pieces. Kodoma (1962) proposed that root piece enlargement may also directly reduce the production of daughter roots because the mother pieces 
Table 1. A chronology and summary of the main research literature relating to the use of root piece planting in sweetpotato.

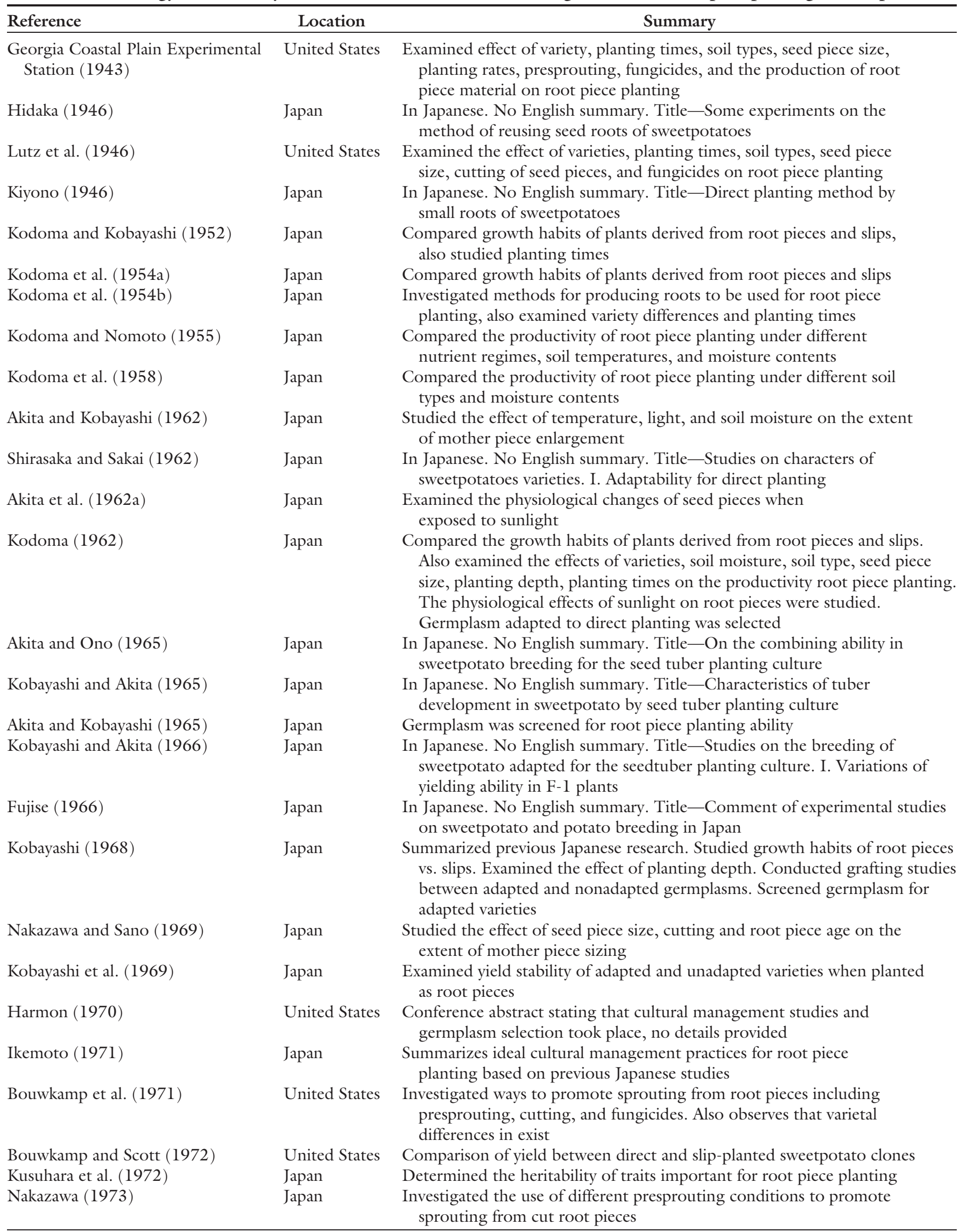


Table 1. (Continued) A chronology and summary of the main research literature relating to the use of root piece planting in sweetpotato.

\begin{tabular}{|c|c|c|}
\hline$\underline{\text { Reference }}$ & Location & Summary \\
\hline Tompkins and Horton (1974) & United States & Investigated the use of ethylene for promoting the sprouting of root pieces \\
\hline Shikata et al. (1975) & Japan & $\begin{array}{l}\text { A report on the release of the first sweetpotato variety developed } \\
\text { specifically for seed piece planting }\end{array}$ \\
\hline Hozyo and Kato (1976) & Japan & Examined of the effects of exposing root pieces to light \\
\hline Allen and Phills (1979) & United States & $\begin{array}{l}\text { Conference abstract. Examined effect of different varieties and cutting } \\
\text { on root piece planting }\end{array}$ \\
\hline Kays and Stutte (1982) & United States & $\begin{array}{l}\text { Examined the effect of cutting of root pieces and root piece size on the } \\
\text { outcome of root piece planting }\end{array}$ \\
\hline Bouwkamp (1982) & United States & $\begin{array}{l}\text { Examined the effect of presprouting treatments and fungicide on root } \\
\text { piece planting. Describe selection methodology for varieties adapted } \\
\text { to root piece planting }\end{array}$ \\
\hline Jeong et al. (1986) & Korea & Compared the effect of different nutrient regimes and planting times \\
\hline Kubota et al. (2000) & Japan & $\begin{array}{l}\text { Compared time and cost saving between planting systems using root } \\
\text { pieces and slips }\end{array}$ \\
\hline Arima et al. (2002) & Japan & $\begin{array}{l}\text { Studied the effect of different hormone treatments on the sprouting } \\
\text { and root growth of root pieces }\end{array}$ \\
\hline Bowen (2010) & United States & $\begin{array}{l}\text { Examined the effect of cutting on sprouting and yield from root pieces } \\
\text { and estimated the heritability of traits important to root piece planting }\end{array}$ \\
\hline
\end{tabular}

will compete with daughter roots for photoassimilates. However, research at North Carolina State University has found no correlation between mother piece size and daughter root yield (Bowen, 2010), so the importance of root piece enlargement to the yield of daughter roots is uncertain.

3) REDUCED STAND ESTABLISHMENT FROM ROOT PIECES. Reduced stand establishment is a problem in root piece planting compared with transplanted slips. For example, early work found that slips displayed on

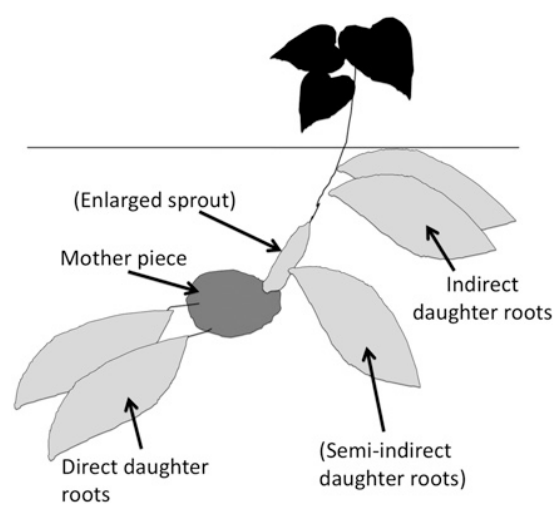

Fig. 1. Sweetpotato root types derived from root piece planting (Kobayashi, 1968); types in parentheses are recognized by the North Carolina State University research group. average $85 \%$ survival, whereas root pieces achieved on average 36\% (Lutz et al., 1946). Reduced plant stands can also lead to higher weed density, further decreasing yield (Bouwkamp, 1982). Reduced stand establishment is thought to be due primarily to the rotting of the root piece in the soil before sprouting. As will be discussed, cutting roots of seed roots is often used to both increase root piece number and to promote sprouting from the distal end of the root. This practice increases the risk of rot by providing an entry point for pathogens, typically soft rot (Rhizopussp.) (Bouwkamp et al., 1971).

4) INFERIOR DAUGHTER ROOT APPEARANCE. For most sweetpotato clones, the physical characteristics of daughter roots produced from a planted root piece are usually inferior when compared with roots produced from transplanted slips (Bouwkamp, 1982; Georgia Coastal Plain Experimental

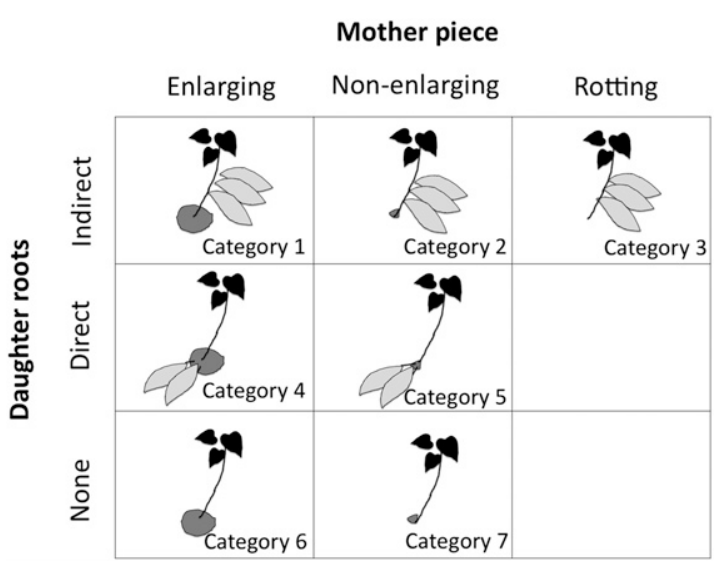

Fig. 2. Sweetpotato plant type classification system derived from root piece planting: 1) indirect daughter root piece enlarging, 2) indirect daughter root piece remaining, but not enlarging, 3 ) indirect daughter root piece disappearing, 4) direct daughter root piece enlarging, 5) direct daughter root piece remaining, and 6) mother piece enlarging with no to very few daughter roots (Bouwkamp, 1982). Note that these are nondiscrete categories. 
Station, 1943; Kobayashi, 1968). Daughter roots produced from root pieces tend to be relatively more misshapen and have rougher skin. Kobayashi (1968) observed that it was direct daughter roots that tend to be misshapen, rather than indirect roots. Our research group has also observed that semidirect roots appear inferior to indirect roots.

5) Reduced Yield STABility. Reliable data regarding yield stability are not widely published, but researchers at the Chugoku Agricultural Experimental Station state that the annual yield stability from clones planted as root pieces is usually less than for the same clones planted as slips (Kobayashi, 1968; Kobayashi et al., 1969).

These five interrelated factors provide a framework for reviewing literature with respect to root piece research throughout the remainder of the review.

\section{The influence of cultural and genetic factors on root piece planting}

Research literature shows that the outcome of root piece planting is influenced by both environmental and genetic factors (Allen and Phills, 1979; Georgia Coastal Plain Experimental Station, 1943; Kobayashi, 1968; Kodoma, 1962; Lutz et al., 1946; Nakazawa, 1973; Nakazawa and Sano, 1969; Phills and Allen, 1979). The following sections address the influence of both cultural and genetic factors on the problems described above.

\section{Cultural factors}

Researchers have widely investigated the use of basic cultural management to address the problems associated with root piece planting. The earliest published research relating to root piece planting in sweetpotato addresses different cultural practices in an attempt to rectify problems associated with planting sweetpotato from root pieces (Georgia Coastal Plain Experimental Station, 1943; Kiyono, 1946; Kodoma, 1962; Kodoma and Kobayashi, 1952; Kodoma et al., 1954a, 1954b, 1958; Kodoma and Nomoto, 1955; Lutz et al., 1946; Nakazawa, 1973; Nakazawa and Sano, 1969). This work generally targeted the problem of root piece enlargement and poor daughter root yield. The cultural factors identified as having the greatest role in dictating the extent of daughter root yield and root piece enlargement were the size of the planted root piece and soil type.

There is a strong positive correlation between the size of a sweetpotato root piece and the extent to which it enlarges; smaller pieces result in reduced enlargement (Kodoma, 1962; Nakazawa, 1973; Nakazawa and Sano, 1969). Smaller root pieces also exhibit reduced sprouting relative to larger ones though (Takatori, 1961; Yamashita, 2000), so smaller roots are prone to reduced stand establishment. So a tradeoff exists between planting a root piece small enough to minimize enlargement but large enough to allow sufficient sprouting for establishment. The ideal root piece size appears to vary between varieties, but is $\approx 40$ to $60 \mathrm{~g}$ (Kodoma, 1962; Yamashita, 2000), although some workers report success with pieces of around $20 \mathrm{~g}$ under field conditions (Bouwkamp, 1982).

Planting on coarser soils results in greater daughter root yield and less enlargement of root pieces than planting on fine textured soils (Georgia Coastal Plain Experimental Station, 1943; Kodoma, 1962; Lutz et al., 1946; Nakazawa, 1973; Nakazawa and Sano, 1969). The underlying mechanism for this effect is unknown and requires investigation, but we propose that there are two possible causes: First, coarser soils are likely to be drier, therefore the root piece acts as source of moisture for aboveground biomass; second, soil moisture dictates whether primordia become roots or shoots, with shoots predominating in drier conditions (Yasui, 1944). Therefore in drier soil more adventitious shoots are produced which may lead to the production of more indirect daughter roots.

Other factors, such as planting date, soil temperature and moisture, and planting depth, influence root piece planting but their effect varies considerably between varieties, seasons, and sites (Kobayashi, 1968; Kodoma, 1962). Generalizations regarding the impact of these cultural practices therefore cannot be made readily. Unpublished research from our root piece studies show a low consistency in ranking of clones between years and sites. We hypothesize that variation reported by other workers may be indicative of genotype by environment interaction.

Interestingly, Japanese researchers found that removing soil from previously planted root pieces completely inhibited mother piece sizing and resulted in the development of daughter root yields that were comparable to using slips (Kodoma, 1962). This is called the "sun exposure" planting method. The effect is independent of the sweetpotato clone used (Kodoma, 1962). The underlying reason for the failure of mother roots to enlarge when uncovered was found to be epidermal thickening and lignification caused by sunlight exposure (Akita and Kobayashi, 1962; Akita et al., 1962a). The sun exposure method is probably not a viable cultural management technique because uncovering planted root pieces on a field scale would pose practical challenges and increase the risk of pest damage. The findings do suggest however that if epidermal thickening and lignification can be induced by other means, such as via chemical treatment, or breeding, mother piece sizing may be reduced.

Reduced stand establishment is also a major problem associated with root piece planting in sweetpotato. The early studies in the United States concluded that both inferior sprouting and rotting of the planted piece were the primary determinants of reduced stand establishment and recommended presprouting the pieces to promote sprouting and using fungicides to prevent rotting (Georgia Coastal Plain Experimental Station, 1943; Lutz et al., 1946). During the 1970s and early 1980s, the University of Maryland confirmed that rotting of pieces in-ground before sprouting is the primary reason for reduced stands and began more comprehensive examination of methods to reduce rotting and increase sprouting of planted root pieces (Bouwkamp, 1982; Bouwkamp and Scott, 1972; Bouwkamp et al., 1971; Kays and Stutte, 1982). Presprouting at elevated temperature and humidity, similar to what is done to sweetpotato roots before bedding, was reported to result in greater sprouting and yields compared with roots that were not presprouted. For example, relative to the control, 5 weeks of presprouting increased total emergence by $34 \%$ and marketable yield by $35 \%$, although the yield difference was not statistically significant (Bouwkamp, 1982). The use of the fungicide dicloran also effectively reduced rotting during presprouting and after planting (Bouwkamp et al., 1971). The magnitude of the 
response to fungicide varied between clones, suggesting the propensity for rotting before sprouting, and the extent of sprouting may be influenced by genetic factors (Bouwkamp, 1982; Bouwkamp et al., 1971). Note that another tradeoff exists here since the rotting of the piece after planting is desirable because it eliminates mother piece sizing.

In potato, seed tubers are cut into pieces to increase propagation material. Cutting sweetpotato storage roots does not have a significant or consistent effect on yield of daughter roots (Bowen, 2010; Kays and Stutte, 1982; Lutz et al., 1946). Sweetpotato storage roots typically exhibit a strong apical dominance so cutting of storage roots will break apical dominance and increase the number of sprouts produced by the distal end of the root (Kays and Stutte, 1982; Takatori, 1961). This allows both the apical and distal pieces to be used for planting. In general, it appears that cutting roots to produce more seed for planting will not have a detrimental effect on yield from root piece planting if a fungicide is used to reduce root piece rotting.

The use of plant hormones as a method to promote sprouting and root growth of planted root pieces has been investigated (Arima et al., 2002; Yamashita, 2000). Yamashita (2000) explored the use of a number of common plant hormones on small (1 to 10 g) sweetpotato root pieces and found that, relative to controls, rooting was increased significantly, from $0 \%$ to $50 \%$ of pieces, after treatment with 100 $\mathrm{mg} \cdot \mathrm{L}^{-1}$ indole-3-acetic acid, and shoot growth was increased 2.8 times relative to controls with $5 \mathrm{mg} \cdot \mathrm{L}^{-1}$ abscisic acid. Yields of storage roots from treated pieces in this work were comparable to the yield obtained from slips. Ethephon, an ethylene delivery chemical, has also been investigated as a means to induce sprouting of root pieces (Tompkins and Horton, 1973). These workers found that root pieces soaked in $1000 \mathrm{ppm}$ of ethephon for $10 \mathrm{~min}$ displayed on average $50 \%$ greater emergence and $34 \%$ greater yields than untreated controls. In addition, the researchers reported that many root pieces treated with ethephon failed to enlarge although they do not provide details. Continuing investigations of ethephon by our research group have found similar results. Hormone treatments may therefore provide a way to facilitate root piece planting in sweetpotato and warrant further investigation.

The above discussion indicates that a number of cultural management practices can improve the outcome of root piece planting. However, these improvements are most successful in terms of reducing enlargement of mother pieces and improving stand establishment. The ability to consistently increase yield, appearance, and yield stability is minimal. Cultural methods therefore cannot completely eliminate the problems inherent with root piece planting. Many studies report variation between clones in terms of adaption to root piece planting (Akita and Kobayashi, 1962; Bouwkamp and Scott, 1972; Georgia Coastal Plain Experimental Station, 1943; Kodoma, 1962; Kodoma et al., 1954b; Lutz et al., 1946; Phills and Allen, 1979; Shirasaka and Sakai, 1962). The ultimate success of root piece planting is likely to be determined by a combination of cultural practices and the selection of appropriate clones.

\section{Genetic factors}

In a diverse collection of germplasm, sweetpotato clones that produce a high daughter root yield and low mother piece sizing when planted from root pieces can typically be found, albeit at a low rate. One way to demonstrate this is to examine "partitioning index." Partitioning index provides a measure of the partitioning of yield between daughter roots and enlarged root pieces [partitioning index $=$ (daughter root yield - mother piece yield $\div$ total yield]. The value varies from 1.00 to -1.00 . A value of 1.00 indicates all yield is daughter roots, -1.00 all yield is root pieces, and 0.00 the yield is evenly divided between the two. Data for two diverse populations show that clones exist with a range of partitioning indexes. About $1 \%$ of clones have partitioning indices of 0.9 or greater (Fig. 3). The heritability $\left(b^{2}\right)$ of the partitioning index is estimated to be relatively high $\left[h^{2}=\right.$ 0.4 to 0.6 (Bowen, 2010)], suggesting it should be possible to select and breed for clones with high partitioning indexes. This would overcome low daughter root yield and mother piece enlargement, two of the main problems associated with root piece planting.

Yield in sweetpotato transplanted from slips is reported to be heritable $\left[h^{2}=0.7\right.$ (Jones, 1986)], however daughter root yield from root pieces was found not to be heritable $\left[h^{2}=0.0\right.$ (Bowen, 2010)]. This would appear
A.

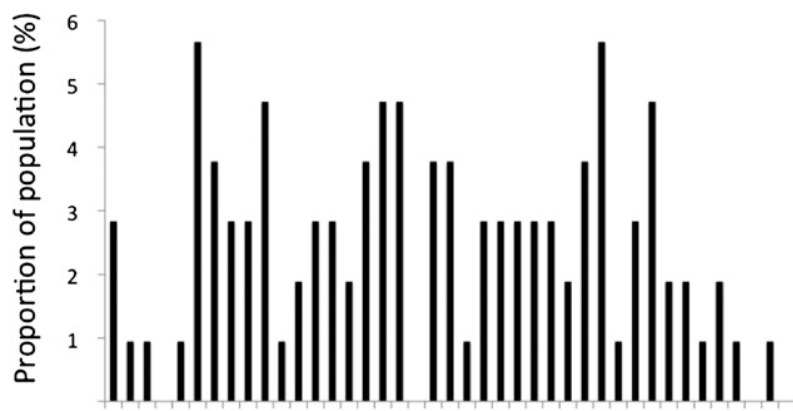

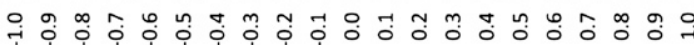

B.

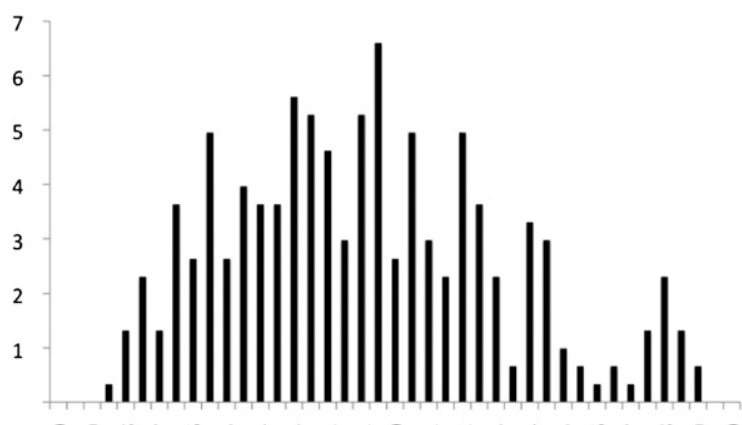

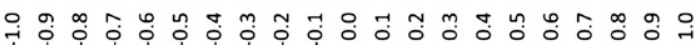

Partitioning index

Fig. 3. The occurrence of sweetpotato clones with different rooting types: (A) 106 randomly selected clones (Kobayashi, 1968); (B) 304 clones from a segregating population (Bowen, 2010). Partitioning index provides a measure of the partitioning of yield between daughter roots and enlarged root pieces [partitioning index $=($ daughter root yield - mother piece yield $) \div$ total yield] 
to contradict the finding that partitioning index is heritable given the value is related to daughter root yield. The reason for these discrepancies are unknown and further investigation is required to determine if breeding can be used to address the problem of yield stability in root piece planting. Related to this, it has been hypothesized that root piece enlargement directly reduces the production of daughter roots (Kodoma, 1962). Reducing root piece sizing would therefore need to be one of the primary objectives of both breeding and cultural work (Kodoma, 1962). However, an examination of data from Bowen (2010) contradicts this, finding only a very weak relationship between yield of daughter roots and partitioning index (Fig. 4). High-yielding clones will therefore not necessarily produce low yields of enlarged mother pieces. These results suggest that high daughter root yield and low mother piece enlargement may need to be selected for separately, and that it could be difficult to breed directly for higher yields.

Variation in root piece sprouting between sweetpotato clones has been observed, and heritability of sprouting is reported to be low to moderate $\left[h^{2}=0.4\right.$ (Jones, 1986) $]$. This suggests that clones with greater seed piece sprouting ability could be developed. However, steps would need to be taken to also avoid sprouting while in storage. Furthermore, Bouwkamp (1982) reported a moderate correlation between clones that fail to exhibit mother piece sizing and those that produce few or less vigorous sprouts. A correlation between these traits would mean that the selection of varieties with high partitioning indices could indirectly select for reduced stand establishment. Examination of data from North Carolina State University field trials did not find a relationship between sizing and sprouting. The nature of this relationship will therefore need to be investigated further.

Relative to direct root types, indirect root types in sweetpotato tend to have a superior appearance and possibly greater yield stability (Kobayashi, 1968). Selecting for clones that produce primarily indirect daughter roots would therefore address problems of inferior daughter root appearance and low yield stability associated with root piece planting. The proportion of clones from a random selection of germplasm that will produce predominantly indirect daughter roots is not published. Nevertheless, indirect daughter root production has been found to have a relatively high heritability $\left(h^{2}=0.54\right)$ and direct daughter root types are moderate $\left(h^{2}=0.29\right)$ (Kusuhara et al., 1972). It should, therefore, be feasible to develop clones with superior appearance and greater yield stability by selecting and breeding for indirect root types.

Japanese efforts demonstrate the feasibility of developing sweetpotato clones adapted to root piece planting via selection and breeding. The Chugoku Agricultural Experimental Station began work to develop clones for root piece planting in 1956 (Kobayashi, 1968). The program screened for root piece planting ability in the second selection cycle, after making an initial selection for varieties with suitable agronomic and quality characters in

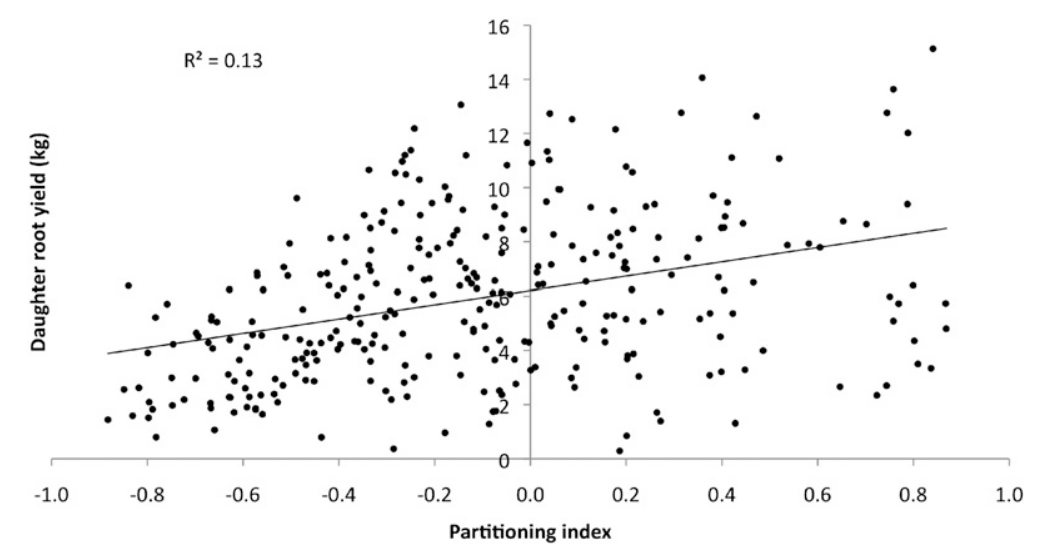

Fig. 4. The relationship between daughter root yield and partitioning index in sweetpotato (Bowen, 2010); partitioning index $=($ daughter root yield - mother piece yield) $\div$ total yield; $1 \mathrm{~kg}=2.2046 \mathrm{lb}$. the first year. This work led to the selection of the clone 'Naeshirazu', a white-fleshed, indirect daughter type that produces large numbers of small roots which can be used as seed and only requires 4 weeks to sprout following planting (Shikata et al., 1975). It was intended for the production of starch and livestock feed. 'Naeshirazu' was released as a commercial variety but was never produced commercially. In 2011, the National Agricultural Research Center for Kyushu Okinawa Region, Japan, released the variety Tamakane (Sakai et al., 2011), an orange-fleshed clone intended for fermentation for liquor that can also be planted via root pieces.

Development of sweetpotato clones adapted to root piece planting can therefore be achieved by including a screening component for root piece planting characteristics into breeding programs. An evaluation of root piece planting characteristics can be included in the second year of screening, after clones have first been screened for desirable agronomic traits and suitability for target end uses. The breeding program at North Carolina State University has adopted this approach. Screening for root piece planting ability can be conducted by planting clones as root pieces and selecting those clones which display high yield and partitioning index, indirect daughter root production, and good sprouting. Given the moderate to high heritability of most traits of interest, development of a recurrent selection program for seed piece planting characteristics should lead to an increase in the adaption of breeding populations to root piece planting over time.

\section{Conclusions and recommendations for future work}

Research literature and the experience of Japanese breeders suggests, given the development of suitable clones and use of appropriate cultural management methods, it should be possible for root piece planting to be used as a viable alternative to slip in sweetpotato. Root piece planting could be particularly useful where root appearance is less critical and could therefore provide an avenue for reducing production costs and permit the economical production of sweetpotato for processed food and industrial end uses. 
It is unclear from the literature if it is possible to develop clones that produce roots with reasonable appearance and size ranges to make them suitable for tablestock markets.

Future work is required to facilitate the development of root piece planting as a commercially viable method of planting sweetpotato. This work should include:

1) Examination of the heritability of traits that will affect the outcome of root piece planting. Breeding efforts for sweetpotato clones adapted to root piece planting will be aided by further heritability studies, particularly of daughter root yield and sprouting ability. There are conflicting reports regarding the correlation between some traits of interest so examination of the nature of the relationship between traits of interest is needed.

2) The further examination of plant hormones and other chemical treatments. The promising results from studies of plant hormones suggest these or other chemical treatments may be used to induce sprouting and rooting of pieces while facilitating epidermal thickening, lignification, rotting, or both of the planted piece. Further evaluation of plant hormones and other chemicals as tools in root piece planting is needed.

3 ) Examination of the developmental physiology and morphology of daughter roots in root piece planting. There is little published work examining the underlying mechanisms responsible for the success or failure of individual sweetpotato clones when planted as root pieces. Understanding the developmental physiology and morphology of storage roots in sweetpotato has been useful for indentifying the relationship between root anatomy and yield of sweetpotato storage roots (Belehu et al., 2004; Togari, 1950; Wilson and Lowe, 1973), but investigations of this type have not been conducted for root pieces. Such studies would be useful to facilitate a better understanding of the results of both cultural management and breeding studies relating to root piece planting.

4) Examination of the practicality of root piece planting in sweetpotato. It is assumed that root piece planting used for potato can also be incorporated into sweetpotato production systems, but little work has be done to demonstrate this. For example, it is unclear whether adapting equipment for root piece production and planting in potato for use in sweetpotato is feasible. It is also unclear whether the lower rate of vegetative increase from root pieces vs. slips will make root piece planting feasible. Investigations of the practical issues surrounding the use of root piece planting in commercial sweetpotato production systems should be conducted.

5) Economic analysis of sweetpotato root piece planting. There is little published work estimating the potential time and economic savings root piece planting may provide over conventional sweetpotato production systems in terms of labor inputs, crop and seed increase potential and ultimately, profitability. A single Japanese study concluded the root piece planting provided little cost and time saving benefits relative to slips (Kubota et al., 2000). Further analysis of this type will be necessary for both guiding and providing justification for cut root piece research in sweetpotato in the future.

New markets for sweetpotato are developing, but their viability will require lower cost production systems. Root piece planting is readily mechanized and could reduce a large cost component of production by reducing labor demands. A 70-year body of work demonstrates that root piece planting in sweetpotato can be as successful as planting from slips under some circumstances, but that a range of problems must be overcome before it can be reliably used for commercial production.

\section{Literature cited}

Akita, S. and M. Kobayashi. 1962. Studies on the control of the mother-root growing of sweetpotatoes. Factors concerning the mother-root growing (in Japanese). Jpn. J. Crop. Sci. 30:127-130.

Akita, S. and M. Kobayashi. 1965. On the tuber developing types of sweet potato bred for seed-tuber planting culture (in Japanese). Jpn. J. Breeding 15:53.

Akita, S., M. Kusuhara, and M. Kobayashi. 1962a. Studies on the control of motherroot growth in sweetpotatoes. Growing process of plants and development of mother-root exposed to the light after sprouting (in Japanese). Jpn. J. Crop. Sci. 30:295-297.

Akita, S. and M. Ono. 1965. On the combining ability in sweet potato breeding for the seed-tuber planting culture (in Japanese). Jpn. J. Breeding 15:53.
Allen, B.M. and B.R. Phills. 1979. Evaluation of sweet potato cultivars and advanced breeding lines for desirable plant production with special emphasis on seedpiece propagation. HortScience 14:124 (abstr.).

Arima, S., M. Yamashita, H. Shibayama, and A. Hoque. 2002. Seedling growth and their field performance of sweet potato (Ipomoea batatas (L.) Lam.) using cut pieces of the tuberous roots (in Japanese). Rpt. Kyushu Branch Crop Sci. Soc. Jpn. 68:77-81.

Belehu, T., P.S. Hammers, and P.J. Robbertse. 2004. The origin and structure of adventitious roots in sweetpotato (Ipomoea batatas). Aust. J. Bot. 52:551-558.

Bouwkamp, J.C. 1982. Research on production of sweet potatoes from cut root pieces. Sweet potato: Proc. First Intl. Symp., p. 191-202.

Bouwkamp, J.C. and L.E. Scott. 1972. Production of sweetpotatoes from root pieces. HortScience 7:271-272.

Bouwkamp, J.C., L.E. Scott, and J.G. Kantzes. 1971. Control of soft rot (Rhizopus sp.) in cut root pieces of sweetpotatoes with 2,6-dichloro-4-nitroaniline. Plant Dis. Rptr. 55:1097-1098.

Bowen, B. 2010. Genetic and cultural management studies of the production of industrial sweetpotatoes from "cut seed pieces". North Carolina State Univ., Raleigh, Masters Thesis.

Estes, E., J. Schultheis, and H. Sampson. 2002. Sweet potato enterprise budget worksheet. Dept. Agr. Resource Econ., North Carolina State Univ., Raleigh.

Food and Agriculture Organization of the United Nations. 2010. FAOSTAT. I May 2011. <http://faostat.fao.org/site/567/ default.aspx\#ancor $>$.

Fujise, K. 1966. Comment on experimental studies on sweet potato and potato breeding in Japan (in Japanese). Jpn. J. Breeding 15:284-286.

Georgia Coastal Plain Experimental Station. 1943. Seed-piece method of planting sweetpotatoes. Georgia Coastal Plain Expt. Sta., Tifton, Mimeograph Paper.

Harmon, S.A. 1970. Evaluation of sweet potato varieties and seedlings for commercial production by the seed piece method of planting. Assn. Southern Agr. Workers 67:140 (abstr.).

Hidaka, M. 1946. Some experiments on the method of reusing seed roots of sweet potatoes (in Japanese). Jpn. J. Crop. Sci. 16: $1-8$.

Hinson, R.A. and J.E. Boudreaux. 2007. Louisiana vegetable crops. Dept. Agr. Econ. Agribusiness, Louisiana State Univ., Baton Rouge. 
Hosokawa, H., H. Fukuzawa, and K. Watanabe. 1998. Mechanized direct planting system for sweetpotato. Trop. Agr. (Trinidad) 75:147-149.

Hozyo, Y. and S. Kato. 1976. Thickening growth inhibition and re-thickening growth of tuberous roots of sweet potato plants (Ipomoea batatas Poiret) (in Japanese). Proc. Crop Sci. Soc. Jpn. 45:131-138.

Ikemoto, S. 1971. Studies on the direct planting of sweet potato (in Japanese). Bul. Chugoku Natl. Agr. Expt. Sta. 20:117-156.

Jeong, B.C., S.K. Oh, K.Y. Park, and S.P. Rho. 1986. Effects of fertilizer amount, planting density and date on growth and tuber root yields in planting sprouted root pieces of sweet potato (in Korean). Res. Rpt. Rural Dev. Administration, Crops 28: 184-188.

Jones, A. 1986. Sweet potato heritability estimates and their use in breeding. HortScience 21:14-17.

Kays, S.J. and G.W. Stutte. 1982. Proximal dominance and sprout formation in sweet potato (Ipomoea batatas (L.) Lam) root pieces. Proc. 5th Intl. Symp. Trop. Root Tuber Crops. p. 41-47.

Kiyono, H. 1946. Direct planting method by small roots of sweet potatoes (in Japanese). Agr. Hort. 21.

Klass, D.L. 1998. Biomass for renewable energy, fuels and chemicals. Elsevier, Sydney, Australia.

Kobayashi, M. 1968. Studies on breeding and vegetative propagation of sweetpotato varieties adapted to direct planting. Bul. Chugoku Natl. Agr. Expt. Sta. Ser. A 16:245-269.

Kobayashi, M. and S. Akita. 1965. Characteristics of tuber development in sweet potato by seed tuber planting culture (in Japanese). Jpn. J. Breeding 15:207.

Kobayashi, M. and S. Akita. 1966. Studies on the breeding of sweet potato adapted for the seedtuber planting culture. I. Variations of yielding ability in F-1 plants (in Japanese). Jpn. J. Breeding 16:57.

Kobayashi, M., S. Akita, S. Ikemoto, and M. Kusuhara. 1969. Studies on breeding of sweetpotato varieties adapted to direct planting. II. Variability of daughter roots yield in different root types (in Japanese). Jpn. J. Breeding 19:19-22.

Kodoma, T. 1962. Ecological studies on the growth of directly planted sweet potatoes (in Japanese). J. Central Agr. Expt. Sta. 1:157-222.

Kodoma, T. and R. Kobayashi. 1952. Studies on the culture of direct sown sweet potato. I. Influence of sowing time of seed tuber upon the growth and yielding of sweet potato (in Japanese). Bul. Kantotozan Agr. Expt. Sta. 3:43-49.

Kodoma, T., R. Kobayashi, and T. Nomoto. 1954a. Studies on the culture of direct sown sweet potato. II. Comparison between growth habits of sweet potato plant on direct sowing with seed tubers and transplanting with sprouts (in Japanese). Bul. Chugoku Natl. Agr. Expt. Sta. Ser. A 6:103-107.

Kodoma, T., R. Kobayashi, and T. Nomoto. 1954b. Studies on the culture of direct sown sweet potato. III. Productivity of seed tuber produced in different transplanting time (in Japanese). Bul. Kanto-tozan Agr. Expt. Sta. 6:108-112.

Kodoma, T. and T. Nomoto. 1955. Studies on the culture of direct sown sweet potato. IV. Productivity of seed tuber produced under different cultural conditions (in Japanese). Bul. Chugoku Natl. Agr. Expt. Sta. 8:104-111.

Kodoma, T., T. Nomoto, and K. Watanabe. 1958. Studies on the growth and yield of sweet potato plant sown directly under different cultural conditions: 1. On the growth and yield under different water contents of soil: 2 . On the growth and yield under different kinds of soil and cultural elevation (in Japanese). Jpn. J. Crop. Sci. 26:225-227.

Kubota, T., S. Saskura, and S. Imazono. 2000. Economical estimation of direct planting in sweetpotato production. Sweetpotato Res. Front 10:5

Kusuhara, M., S. Shikata, and H. Namitome. 1972. Studies on the selection of mother plants in breeding sweet potatoes suitable for direct planting. I. Characters of existing varieties and strains, and mother-plant selection (in Japanese). Bul. Chugoku Natl. Agr. Expt. Sta. 21:65-87.

Loebenstein, G. and G. Thottappilly. 2009. The sweetpotato. Springer, New York.

Lutz, J.M., M.T. Deonier, and C.E. Steinbauer. 1946. Studies on possibilities and limitations of the seed piece method of planting sweetpotatoes. Proc. Amer. Soc. Hort. Sci. 48:443-448.

Martin, D.A., R.D. Myers, and C.A McClurg. 2000. Growing sweet potatoes. Maryland Coop. Ext., Univ. of Maryland, College Park

Mississippi State University. 2007. Traditional and organic vegetables 2008 planning budgets. Mississippi State Univ., Dept. Agr. Econ., Mississippi State.

Nakazawa, A. 1973. Study on the direct planting of cut sweet potato tubers (in Japanese). J. Central Agr. Expt. Sta. 19: 101-165.

Nakazawa, A. and H. Sano. 1969. Studies on thickening of mother tubers in directly planted sweet potato by cutting piece of seed tubers (in Japanese). Jpn. J. Crop. Sci. 38:132-136.

Phills, B.R. and B.M. Allen. 1979. Evaluation of selected sweet potato cultivars for seedpiece propagation. HortScience 14:124 (abstr.).

Sakai, T., K. Katayama, Y. Kai, and M. Yoshinaga. 2011. New sweetpotato cultivar "Tamaakane" suitable for brewing and direct planting. Sweetpotato Res. Front 25:3

Shikata, S., M. Kobayashi, M. Kusuhara, S. Ikemoto, H. Namitome, S. Akita, and M. Ono. 1975. Breeding the new sweet potato variety Naeshirazu for direct planting (in Japanese). Bul. Chugoku Natl. Agr. Expt. Sta. 24:97-108.

Shirasaka, S. and K. Sakai. 1962. Studies on characters of sweet potatoes varieties I. Adaptability for direct planting (in Japanese). Proc. Crop Sci. Soc. Jpn. (Kyushu ed.) 16: 8-12.

Takatori, F.H. 1961. Influence of seed piece size and cutting on the production of sweet potato shoots. J. Amer. Soc. Hort. Sci. 77:475-478.

Togari, Y. 1950. A study of tuberous root formation in sweet potato (in Japanese). Bul. Natl. Agr. Expt. Sta. Tokyo 68:1-96.

Tompkins, D.R. and R.D. Horton. 1973. Plant production by sweetpotato roots as influenced by ethephon. HortScience 8: $415-416$

Tompkins, D.R. and R.D. Horton. 1974. Sprouting of sweetpotatoes from root pieces as influence by gibberellic acid or ethephon. HortScience 9:392-393.

U.S. Sweet Potato Council. 2011. The United States Sweet Potato Council Inc. 1 May 2011. <www.sweetpotatousa.org>.

Wilson, L.A. and S.B. Lowe. 1973. The anatomy of the root system in West Indian sweet potato [Ipomoea batatas (L.) Lam.] cultivars. Ann. Bot. (Lond.) 37:633-643.

Yamashita, M. 2000. Nurturing of plantlets using cut seed pieces from the storage roots of sweet potatoes (Ipomoea batatas (L.) Lam.) and their productivity in the field. Plant Prod. Sci. 3:259-267.

Yasui, K. 1944. Notes on the propagation of sweet potato, Ipomoea batatas Lam. I. The adventive bud formation in the roottuber (in Japanese). Proc. Imperial Acad. 20:41-44.

Ziska, L.H., G.B. Runion, M. Tomecek, S.A. Prior, H.A. Torbet, and R. Sicher. 2009. An evaluation of cassava, sweet potato and field corn as potential carbohydrate sources for bioethanl production in Alabama and Maryland. Biomass Bioenergy 33:1503-1508. 